scured the sun before the ravages of the influenza of 1782, and he supposes "that the material which thus rendered the air unwholesome and muddy, probably caused the epidemic catarrh which prevailed in that year." Some sensible people in this country have, moreover, told me, that the influenza of $184: 3$ was in like manner ushered in by continuous dark and noisome fogs. Be this as it may, there is, in $m y$ opinion, no doubt that this our last epidemical influenza was in some way or other occasioned by the aforesaid dense and offensive fog; and it was, moreover, very remark able, that the smell of this fog, being quite unlike com. mon fogs, was that of a highly encentrated ozonic gas, which immediately irritated the mucous membrane of the lungs, and most likely also the other mucous mem. branes of the body.

\section{Asssociation ẩntellinence.}

\author{
SOUTH-EASTERN DRANCH.
}

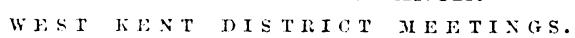

Tine third meeting for the session was held at Graves. end on March 2ith, lis03; 'T. Heckstain, Smith, Esq., President of the Branch, in the chair. There were also present twenty-seven members and visitors.

New Hembers. 'Two new members were proposed and elected agreeably to the rules of the Association; viz., Joseph Stewart Burton, Esq., Woodlands Lodge, Black. heath; and John Christopher Armstrong, Esq., of Gravesend.

Death of Mr. G. W. Martin. The meeting desired to express their sympathy with Dr. Adam Martin of Ro. chester, in the bereavement which he has lately sus. tained in the death of his son.

The Secretaryship. Dr. Dulvey tendered his resignation as honoraly secretary to the West lient district meetings, on the plea of ill-health and family affliction.

Mr. J. M. Buntun proposed, and Mr. Hunt seconded, the resolution to accept Dr. Julvey's resignation; and they, at the same time, testified to the great ability, zeal, and success of Dr. Dulvey's administration of the duties of secretary.

Mr. Fry followed in the same strain, and stated that the institution of the district meetings was solely due to Dr. Dulvey.

Dr. Dunvey returned thanks, and said that he rejoiced to see the district meetings in so flourishing a condition on his cessing to hold office.

It was then proposed by Dr. Ansistroxg, and seconded by Mr. Frx,

"That Dr. Frederick James Brown of Rochester sbould be the secretary."

This resolution was put and carried unanimously.

Communications. The following communications were made :-

1. Ascites and Anasarca in the Fotus; a successive case $t$ o that reported in the autumn of 1861 . By J. M. Burton, Eiq.

2. A conversation was induced by Mr. IIunt (of London) on the Epidemic Prevalence of Scabies at the present time. One gentleman recommended for the cure of the disease sleeping in powdered sulphur strewed over the sheets. The eruption now prevalent is said to somewhat resemble rupia.

3. Mr. Durham of Guy's Hospital demonstrated the use of the Laryngoseope. He was assisted by Mr. Hilder, who kindly made himself the subject of the experiments.

The uswal thanks were voted, when the members and visitors aljourned to dinner.

\section{ERRATA.}

At page $333: 3$, column 1, of last week's Journar, in the $C$ list of new members admitted into the Metropolitan Counties Branch, for " Clark, Alfred, M.D.", read "Clark, Andrew, M.D."; and for "Norton, Richard, M1.D.", read "Norton, Tobert, M.D."

\section{aleports of Sorieties.}

ROYAL MEDICAL AND CHIRURGICAL SOCIETY.

Tensday, Mlimir 24th, 1863.

Richum l'artrid (ie, Ese., F.R.S., President, in the Chair.

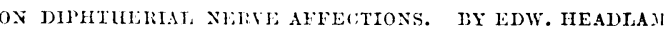
GREENHOW, M.1), F.R.C.T.

THe author began hy stating that the epidemic sore. $\infty$ throat which, under the name of diphtheria, had latterly of engaged so much attention, was well knowr to be fol- $\infty$ lowed by nervous phenomena of a peculiar kind. These o consisted chiefly of impaired, excessive, or perverted sensibility, together with more or less complete paralysis of the muscles of the fauces, pharynx, tongue and lips, extremities, trunk, and neck; the frequency of the occurrence of these symptoms in the several sets of muscles being nearly in accordance with the order in which he had placed them, the first named being the most 5 frequently and the last the least frequenily affected. The author had had the opportunity of watching the course of several cases of these diphtherial nerve affections in patients under treatment at the Middlesex Hospital, and the present paper was in a great degree based on those observations. He did not mean to infer that every attack of diphtheria was followed by some of these secondary nerve affections, for he had seen patients re. cover perfectly without experiencing ary of them; nor to assert that their intensity was always proportioned to the severity of the primary disease, for he had sometimes seen them follow comparatively mild attacks of diph. theria. Nevertheless, as a general rule, he had certainly observed these nerve affections to be more frequent after the worst cases of diphtheria, and to bear some propor. tion even to the local severity of the attack; he had noticed, for instance, that the paralysis and ancsthesia were sometimes more complete on that side of the fauces which had been most severely affected by the primary disease.

The author had found that a brief period of convales cence-generally not exceeding a few days, but in rare cases extending to weeks-almost always intervened be- N tween the disappearance of the sore-throat and the accession of the nerve symptoms; and cases had fallen under his notice in private practice in which patients who had recovered sufficiently from diphtheria to be sent from home for change of air, had subsequently 0 fallen into a lielpless condition from diplitherial paraly- స్ sis. The fact of this interval seemed to him important, inasmuch as it went far to show that the paralysis could not be entirely attributable either to the albuminuria which so often accompanies the acute stage of diphtheria, or to the anamia which closely follows it, as patients $?$ had often got rid of the former symptom, and had even begur in some cases to regain flesh and strength, before the accession of the paralytic symptoms.

The author had observed that these nerve affections do not at once attain their maximum of intensity, but are progressive even in the same sets of muscles; and also that if several of the sets of muscles which he had enumerated should be attacked in the same individual, they do not become affected all at once, but in succes- 